\title{
A Mathematical Method to Keep the Passenger Throughput at an Airport Security Checkpoint
}

\author{
Kai Wang ${ }^{1, a}$ \\ ${ }^{1}$ North China Electric Power University, Baoding 071003,China \\ awk1248052647@126.com
}

Keywords: Petri Net, Object Net++, Passenger Throughput.

\begin{abstract}
In order to solve the congestion problem caused by the more strict security check, we developed a mathematical method based on the Petri net model and the queuing theory. First, we get a linear fitting from the A column of data collected according to the queuing theory [1]. And we obtain the distribution of passengers' arrival time. Next, we get the time of every link from the weighted average of other data. The time of one passenger move to the next position also is taken into consideration. After that, we build two optimization models to determine how to solve the problem mentioned in the title. First, we formulate a whole security check Petri net to give a solution according to the Illustration of the TSA Security Screening Process by using Visual Object Net++.By analyzing this model and optimize it, we obtain the optimal solution. Apart from the Petri net model, we develop the virtual queue model based on the queuing theory. It can increase the utilization efficiency of the passenger's time and improve the congestion problem in airport security checkpoints. Finally, we provide some suggestions for the security mangers. For example, provide the individual security check for the pre-check passengers and adjust the number relationship between the millimeter wave body scanner and the X-Ray scanner and so on.
\end{abstract}

\section{Introduction}

Following the terrorist attacks in the US on September 11, 2001, airport security has been significantly enhanced throughout the world. Airports have security checkpoints, where passengers and their baggage are screened for explosives and other dangerous items. The goals of these security measures are to prevent passengers from hijacking or destroying aircraft and to keep all passengers safe during their travel. However, airlines have a vested interest in maintaining a positive flying experience for passengers by minimizing the time they spend waiting in line at a security checkpoint and waiting for their flight. Therefore, there is a tension between desires to maximize security while minimizing inconvenience to passengers. We want to explore the flow of passengers through a security check point and identify bottlenecks by developing one or more model(s) and identify where problem areas exist in the current process. Determine two or more potential modifications to improve passenger throughput and reduce variance in wait time in view of the current process. Put modifications into models to demonstrate how this modifications impact the process

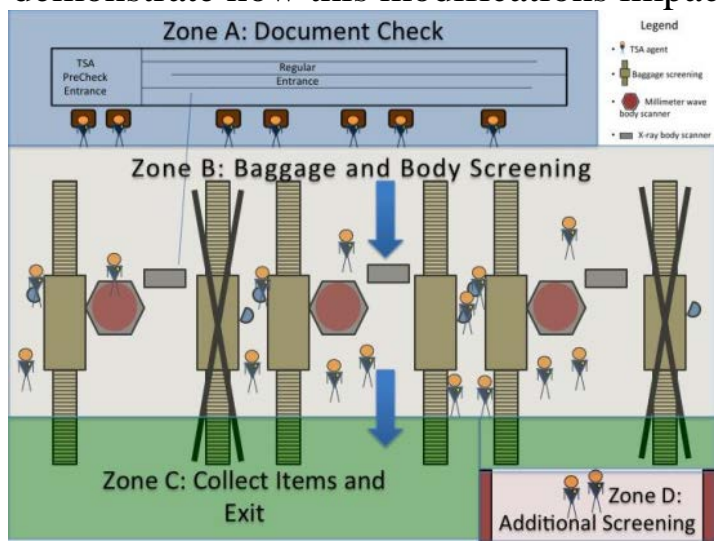

Fig. 1.Illustration of the TSA Security Process 


\section{Model Developing}

\subsection{Introduction}

Petri nets are state-transition systems that extend a class of nets called elementary nets. The elements of Petri nets are place, transition, arc and token. Besides, Petri nets have an exact mathematical definition of their execution semantics, with a well-developed mathematical theory for process analysis ${ }^{[2]}$.

So we develop a whole security check Petri net to give a solution according to the Illustration of the TSA Security Screening Process by using Visual Object Net++.

The virtual queue model ${ }^{[3]}$ is adding a new virtual queue into the previous queue. It also means that a passenger can occupy a place in line by using a machine, even though he doesn't wait in the normal queue. And they must arrive at the queue before the time requested, if not he will be disqualified.

\begin{tabular}{|c|c|}
\hline Symbols & Description \\
\hline $\mathrm{A}(1,2)$ & Document pre-check \\
\hline $\mathrm{B}(1,2,3,4)$ & Regular document check \\
\hline $\mathrm{T}(1,2,3)$ & Prepare for security check \\
\hline$(\mathrm{C}, \mathrm{E}, \mathrm{G}) \cdot 1$ & Passengers 'wait for check' \\
\hline$(\mathrm{C}, \mathrm{E}, \mathrm{G}) \cdot 2$ & Passengers accept check \\
\hline$(\mathrm{C}, \mathrm{E}, \mathrm{G}) \cdot 3$ & Wait for the check result \\
\hline$(\mathrm{C}, \mathrm{E}, \mathrm{G}) \cdot 4$ & Passengers pass the check \\
\hline$(\mathrm{C}, \mathrm{E}, \mathrm{G}) \cdot 5$ & Wait for belongings and bins \\
\hline
\end{tabular}

\begin{tabular}{|c|c|}
\hline Symbols & Description \\
\hline$(\mathrm{D}, \mathrm{F}, \mathrm{H}) \cdot 1$ & $\begin{array}{l}\text { Belongings and bins wait for } \\
\text { X-ray screening. }\end{array}$ \\
\hline$(\mathrm{D}, \mathrm{F}, \mathrm{H}) \cdot 2$ & $\begin{array}{c}\text { Belongings and bins accept } \\
\text { check }\end{array}$ \\
\hline$(\mathrm{D}, \mathrm{F}, \mathrm{H}) \cdot 3$ & Wait for the check result \\
\hline$(\mathrm{D}, \mathrm{F}, \mathrm{H}) \cdot 4$ & $\begin{array}{c}\text { Belongings and bins pass the } \\
\text { check }\end{array}$ \\
\hline$(\mathrm{D}, \mathrm{F}, \mathrm{H}) \cdot 5$ & Wait for passengers \\
\hline $\mathrm{L}(1,2,3)$ & Collect item and exit \\
\hline $\mathrm{P} 1$ & The gather of passengers \\
\hline $\mathrm{P} 2$ & $\begin{array}{l}\text { The gather of passengers who } \\
\text { pass the security check }\end{array}$ \\
\hline
\end{tabular}

Fig. 2.The detailed symbol of the Petri net model

\subsection{The Foundation of Model}

The security check Petri net model is as follows:

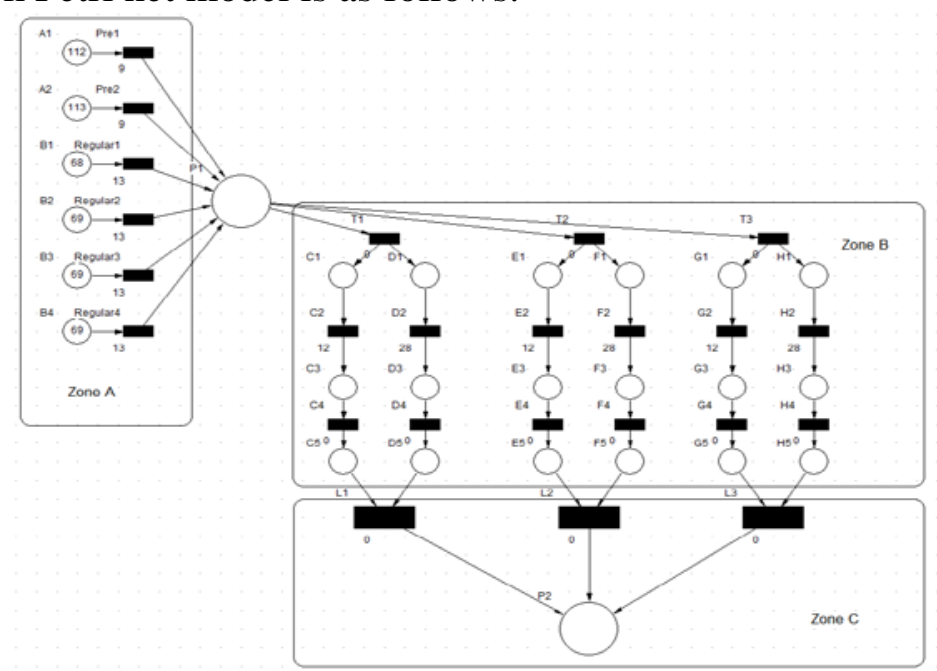

Fig. 3.The basic Petri net model

The results after the run are shown in the following picture: 


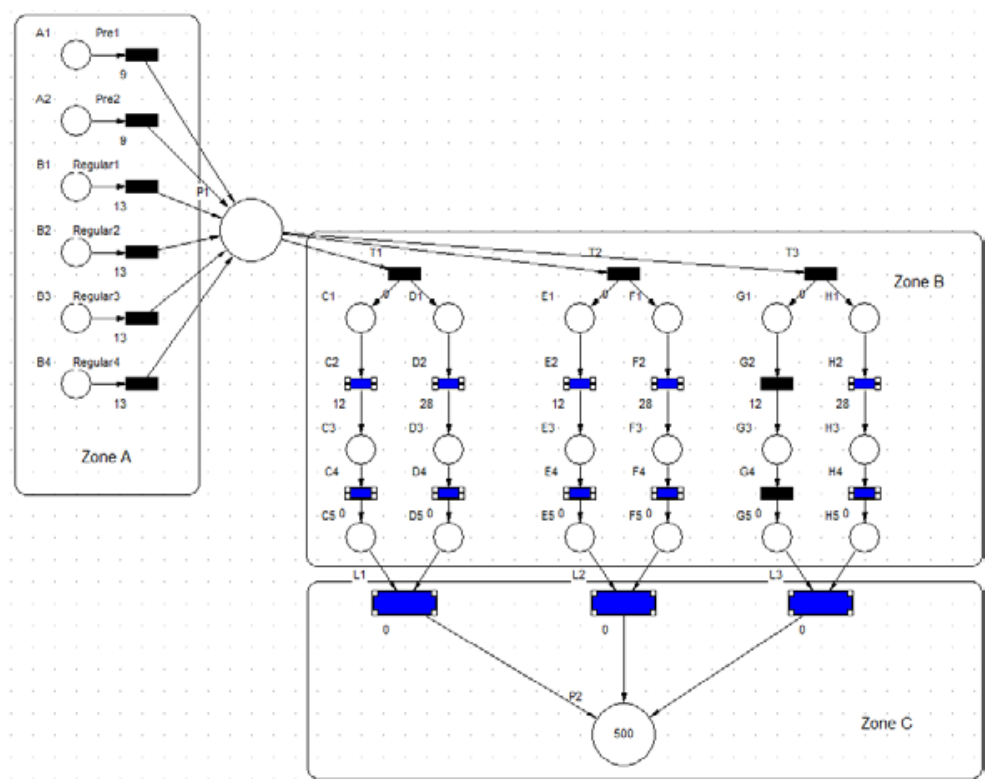

Fig. 4.The results of the run

And we draw a series of conclusion from the process that the major bottleneck is the part of belongings and bins wait for X-ray screening. And the secondary bottleneck is the part of the passengers wait for check and the passengers wait for their belongings and bins.

According to the result of the above, we tried to use the virtual queue model to solve the problem.

The passenger traffic of airport is so large that we need to confirm the rate of virtual queue passengers in the whole passengers. For the convenience of calculation, we assume that there are 30 passengers choose the virtual queue per hour. These passengers need come back to the front of the queue within the required time. Ordinary passengers still need according to the principle of first come first service to accept security check

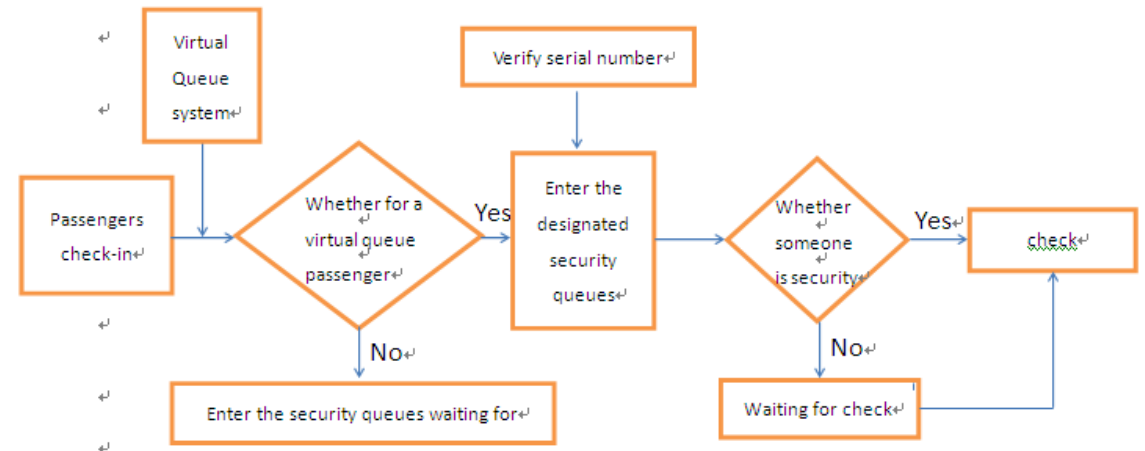

Fig. 5.The flow chart of virtual queue model

We using the Petri Net model to predict the time after carry out the system of virtual model.

Table 1.The time of different situation

\begin{tabular}{|c|c|c|c|c|c|}
\hline \multirow{2}{*}{ Space of time } & \multirow{2}{*}{$\begin{array}{c}\text { No Virtual } \\
\text { Queue } \\
\text { Wait time }(\min )\end{array}$} & \multicolumn{2}{|c|}{ Part of Virtual Queue } & \multicolumn{2}{|c|}{ All of Virtual Queue } \\
\hline & & $\begin{array}{l}\text { Wait time } \\
(\min )\end{array}$ & $\begin{array}{c}\text { Reduced } \\
\text { percentage }\end{array}$ & $\begin{array}{l}\text { Wait time } \\
(\min )\end{array}$ & $\begin{array}{c}\text { Reduced } \\
\text { percentage }\end{array}$ \\
\hline $7: 00 \sim 7: 30$ & 15.917 & 11.330 & $28.82 \%$ & 3.579 & $77.51 \%$ \\
\hline 7: 30 8: 00 & 16.002 & 12.032 & $24.81 \%$ & 4.106 & $74.34 \%$ \\
\hline 8: $00 \sim 8: 30$ & 15.876 & 11.822 & $25.54 \%$ & 3.682 & $76.81 \%$ \\
\hline 8: 30 9: 00 & 15.008 & 11.003 & $26.67 \%$ & 3.501 & $76.67 \%$ \\
\hline
\end{tabular}




\section{Conclusions}

In the case of no virtual queue, the waiting time of passengers was 16 minutes which was a long time. The waiting time has a certain extent when virtual queue system was implemented. When some passengers involved in the virtual queue, the waiting time of passengers was 11.54 minutes, which was reduced by 27 percent compared with the normal queue. When all of passengers involved in the virtual queue, the wait time was 3.717 minutes, which was reduced by 76.8 percent compared with the normal queue.

\section{References}

[1] ZHENWU Zhao, JIANJUN Ma. Development trend and research of civil aviation airport about the system of security queue[J].Integrated transport,2016,(10):64-69.

[2] JINSONG Zhang. Research on Modeling and Simulation of Passenger Departure Flow in Hub Airport Based on Petri Net[D].Civil Aviation Flight Academy of China,2015.

[3] JIANJUN Ma. Application of virtual queue in Civil Aviation Security Inspection System[J].Science technology and innovation,2016,(19): 34-35. 